\title{
Application of the Bayesian New Keynesian DSGE Model to Polish Macroeconomic Data
}

\author{
Janusz Sobieraj $^{1}$, Dominik Metelski ${ }^{2}$ \\ ${ }^{1}$ Warsaw University of Technology \\ al. Armii Ludowej 16, 00-637, Warsaw, Poland \\ E-mail.jsob.@il.pw.edu.pl \\ ${ }^{2}$ University of Granada \\ Campus Cartuja, 18071 Granada, Spain \\ E-mail.dmetelski@ugr.es; (correspondingauthor) \\ cross $^{\text {ref }}$ http://dx.doi.org/10.5755/j01.ee.32.2.27214
}

In the paper we estimate a simple New Keynesian Dynamic Stochastic General Equilibrium NK DSGE model on the basis of Polish macro data from the period 2000-2019. The model is specified similarly to Gali (2008) with the use of the Bayesian approach. The NK DSGE model combines the advantages of both structural models and time-series models and, therefore, shows a significant degree of alignment with empirical data. The Bayesian estimation is based on the prior distribution of the model input parameters, which are later compared with the posteriors. The results obtained allow for assessing the persistence of responses to technological, inflationary and monetary policy shocks. On the basis of the NK DSGE model, we formulate a perception of macroeconomic interactions, e.g. nominal interest rates' association with inflation and the output gap. In other words, the NK DSGE model provides a better understanding of the relationship between interest rates, inflation and the output gap. This in turn makes it easier to understand the monetary policy response function.

Keywords: Dynamic Stochastic General Equilibrium; New Keynesian DSGE Model; Bayesian Approach; Technological, Inflationary and Monetary Shocks; Polish Macro-Economy; Metropolis-Hastings.

\section{Introduction}

Dynamic Stochastic General Equilibrium (DSGE) modelling is a method for explaining economic phenomena such as the effects of economic policy and business cycles (i.e. changes of real GDP) from a macroeconomic perspective. DSGE models are based on general equilibrium theory and microeconomic fundamentals, which they incorporate into econometric methodologies. It should be stressed, however, that although this methodology has been known for nearly 40 years, its quantitative assessment has been conducted for a long time without formal statistical procedures.

The classical quantitative DSGE models are those proposed by Kydland and Prescott and Long and Plosser in the early 1980s (Kyndland \& Prescott, 1982; Long \& Plosser, 1983). They can also be described as optimisation models based on microfunctions, and more importantly, they constitute a significant part of macroeconomic publications. They can be viewed as multidimensional representation of stochastic processes for data; simple models impose very strong constraints on actual time series and in many cases give way to less restrictive specifications such as vector autoregressions (VARs) ${ }^{1}$. Many authors also compare DSGE models' estimates with VAR-type specifications, treating the latter as benchmarks

${ }^{1}$ A VAR model is a generalisation of the univariate autoregressive model for forecasting a vector of time series for making predictive performance comparisons. An example of that is the study by Liu and Gupta (2007), who conducted such a comparison in the context of the South African economy.

The development of the DSGE model-based approach meant that microeconomic fundamentals were incorporated into the macroeconomic models. The specific types of DSGE models are the real business-cycle (RBC) $)^{2}$ models, pioneered by Kyland and Plosser (1982), which take into account the optimising decisions of individual agents and reflect the aggregated economic relationships.

DSGE models allow for modelling the behaviour of individual agents, and, therefore, should not be treated as an attempt to predict the effects of a change in economic policy solely on the basis of relations observed in historical data, as they contain a component related to expectations. Creating forecasts solely on the basis of historical data has been subject to criticism by some scientists (Farmer, $1991)^{3}$.

Under the RBC theory, business cycles are "real" and they reflect the most efficient performance of the economy

\footnotetext{
${ }^{2}$ Real business-cycle theory (RBC theory) encompasses a group of classical macroeconomic models that explain cyclical fluctuations by means of real shocks (as opposed to nominal ones).

${ }^{3}$ It's about Lucas' critique. The Lucas criticism, named after Robert Lucas' study on macro-economic policy making, claims that it is naive to try to predict the effects of a change in economic policy solely on the basis of the relationships observed in historical data, especially highly aggregated historical data.
} 
in terms of its structure. In other words, cycles are the natural sequence of things and they have to be perceived in the context of correcting market imperfections. The actual shocks that affect the economy, such as technological or inflationary shocks, can also be explained in a similar way. However, the RBC models do not incorporate monetary shocks, which also have some impact on the economy. However, it is not that monetary crises are not reflected in the real economy. On the contrary, they manifest themselves in the real economy and imply some real effects. Moreover, the RBC models have been criticised for an overly theoretical approach, which is not entirely confirmed by empirical results; these models are aimed to reflect aggregate technological shocks and describe their effects and the dynamics of the business cycle. However, their predictive performance leaves much to be desired. In other words, the theoretical results generated by these models are in no way confirmed by empirical evidence, i.e., by what is observed in the real economy. In the context of this criticism, the RBC model has been modified by adding new functions to it. For example, there was a problem consisting in the incomplete price elasticity in these models, which was corrected with an inclusion of the Calvo-type pricing method. Such assumptions in turn gave rise to the New Keynesian DSGE model (both basic and canonical). Compared to the RBC models, New Keynesian DSGE models are much more complex. However, there is still plenty of criticism regarding these models. For example, NK DSGE models have been criticised for their excessive stylisation (Bekiros \& Paccagnini, 2014), which may impede their direct use with raw data. Also, an extensive criticism of DSGE models can be found in the papers of Korinek (2017) and Stiglitz (2018). In addition, there is some criticism with regards to the poor predictive results of these models (Bekiros \& Paccagnini, 2014) and the lack of sector-specific details that would allow to extract any meaning from such analyses (Pollitt, 2020). Such details may in fact be important in situations of sudden financial crises (such as the one in 2008-2009) or in situations with which the world is currently struggling, i.e. the coronavirus pandemic. As is known, COVID-19 causes greater drop in activity for some sectors (e.g. tourism, transport, etc.) and in the case of some sectors (e.g. medical sector) it contributes to an improvement in their performance. DSGE models are believed to be attached to a false mast of equilibrium, as they assume that it only takes some time for the post-crisis economy to return to the state of equilibrium known from the pre-crisis world. This, however, does not exactly have to be the case. DSGE models were considered almost useless during the 2008-2009 financial crisis (Pollitt, 2020). However, in a situation of relative market stability, they seem to be working quite well. Hence, the interest of central banks in their adoption. Moreover, the critique of DSGE models has been thoroughly addressed in a very constructive way by Christiano et al. (2018), who in fact largely negated many of the arguments brought up earlier by Korinek (2017) and Stiglitz (2018). For the purposes of this paper we intend to estimate the NK DSGE model based on data for the Polish economy from the period 2000:Q1-2019Q4. In our study, we use the Bayesian approach to estimate the model. Moreover, we want to verify the response of the examined variables to technological, inflationary and monetary policy shocks. Different methodologies can be used to estimate these types of models, e.g. maximum probability methods, as well as different Bayesian approaches or traditional comparison models, e.g. random walk (Smets \& Wouters, 2004; Adolfson et al., 2007). In our model we use the Bayesian tools to estimate structural parameters and to study the impact of frictions (i.e. the frequency of price adjustments). This type of analysis with the use of advanced Bayesian methods is applicable for monetary policy analysis and macroeconomic forecasting.

Firstly, our objective is to develop a simple NK DSGE model for the Polish economy (covering data from the last 20 years), which will provide an overview of some macroeconomic indicators, such as nominal interest rates, inflation and the output gap. Secondly, we want to illustrate the impulse-responses to orthogonalised shocks in technology, inflation and monetary policy.

The remaining part of the paper comprises a review of the literature on DSGE models, their design, microfoundations underlying the simple NK DSGE models, and detailed characteristics of the model under construction. Also, we discuss the econometric methodology and the data used for developing the model (with particular attention paid to appropriate filtration and transformation of the data employed). Finally, we provide the conclusions of the study.

\section{Literature Review}

DSGE models were first developed by Kydland and Prescott (1982) in the early 1980s. Initially, the RBC models enjoyed the greatest popularity, however, too much importance in explaining business cycles was attributed in these models to aggregate fluctuations, whereas at the same time they depreciated the importance of monetary and fiscal policies. Over the years these models have evolved and improved significantly (Ghent, 2009). They began to factor in price stickiness in the sense of Calvo (1983), monopolistic competition, wage rigidity, etc. (Erceg et al., 2000). Ghent (2009) examined the predictive performance of the RBC models and showed how (based on model specifications) working hours respond differently to productivity (measured by TFP) shocks. Despite different structural characteristics, DSGE and DSGE$\mathrm{VAR}^{4}$ models had similar forecasting accuracy and showed some superiority over VAR models.

Smets and Wouters (2004) were among the first to explore the usefulness of contemporary sticky-price dynamic stochastic general equilibrium (DSGE) models based on Bayesian estimation techniques as useful forecasting tools for central banks. In order to assess their prognostic performance, they adopted theoretical vector autoregressions as a reference (i.e. for comparison purposes). Smets and Wouters (2004) showed how to obtain calculations of the full distribution for inflationary risk forecasts with the use of the posterior model distribution. The usefulness and practicality of DSGE

\footnotetext{
${ }^{4}$ A DSGE-VAR is a VAR model where a DSGE model implies some prior distributions for coefficients and the covariance matrix of innovations.
} 
models results from their structural nature and the fact that they allow for the implementation of different policy paths and, consequently, provide estimates of macroeconomic forecasts. Also, DSGE models facilitate the analysis of structural sources of forecasting errors. For example, by means of DSGE models Smets and Wouters (2004) analysed macroeconomic developments in the euro area since EMU was established. They also added real and nominal price rigidity and habits formation, while estimating their first model of this type for the Euro Zone. In turn, Christiano et al. (2005) in order to explore the effects of money shocks, introduced capital use and investment adjustment costs into the DSGE model. Adolfson et al. (2005) extended the DSGE model by incorporation of the characteristics of an open economy into its specification. Similarly to Smets and Wouters (2004), Adolfson et al. (2007) also studied the predictive performance of DSGE models (estimated with the use of the Bayesian methodology) for the euro area, although their analysis perspective was narrowed down to 1994Q12002Q4 period. They showed that forecasting performance of such models compares well with vector autoregression (VAR) and vector error correction models (VECM). For the estimation of these models, there may be used both maximum probability methods and different Bayesian approaches, or traditional comparison models, e.g. random walk. The open economy DSGE model proposed by Adolfson et al. (2007) was free of the constraints and problems found in previous generations of similar models.

The financial crisis in 2008-2009 gave rise to a new group of DSGE models which involved the financial sector and its frictions. There is a whole line of papers devoted specifically to this topic (Curdia \& Woodford, 2009; Christiano et al., 2010; Gertler \& Karadi, 2011) $)^{5}$. For example, Curdia and Woodford (2009) introduced the banking sector, however, the extension of the New Keynesian (NK) model which included the credit channel did not reveal the necessity for any particular changes in the optimal monetary policy. Moreover, by extending the standard monetary DSGE model and including the banking sector and financial markets in it, Christiano et al. (2010) strived to prove that financial factors are the main determinants of economic fluctuations. In the recent financial crisis of 2008-2009 they were critical triggers and propagators. Christiano et al. (2010) argues that financial intermediation becomes an important systemic force and critical trigger and propagator of increasingly frequent crises $^{6}$. Gertler and Karadi (2011), on the other hand, examined banks' incentives for taking excessive risks. Financial frictions were also taken into account by Kolasa and Rubaszek (2015), who examined the differences between DSGE models with and without different types of frictions. Their study showed that factoring in financial market imperfections does not necessarily improve the accuracy of point forecasts in the post-crisis period, while the average quality of forecasts' density deteriorates. In the case of Kolasa and Rubaszek's

\footnotetext{
${ }^{5}$ It can be said that Bernanke et al. (1999), while studying the effects of financial friction on the business cycle, were ahead of their time.

${ }^{6}$ Agency problems in financial contracts, liquidity constraints on banks and shocks that change the perception of market risk and impact financial intermediation.
}

(2015) study, housing market frictions proved to yield the results which turned out to be superior to both the frictionfree benchmark and the alternative that takes into account financial frictions in the corporate sector ${ }^{7}$. Also, Del Negro and Schorfheide (2013) reviewed the forward-looking results of the DSGE models and showed how to use these models for different purposes, i.e. for forecasting, storytelling and policy experimentation, etc. Wickens (2014) demonstrated that the forward-looking dynamics of the DSGE models, consisting of expected values of future exogenous variables, are difficult to forecast accurately. Therefore, these models should not be tested in terms of their predictive effectiveness.

When it comes to estimation of a DSGE model, the Bayesian technique allows to determine the posterior distributions of the model parameters. A higher prognostic performance of DSGE models compared to VAR \& $\mathrm{BVAR}^{8}$ models is a result of the limitations imposed by economic theories that are implemented in these models (Rubaszek \& Skrzypczynski, 2008).

To analyse the Polish economy, we use the New Keynesian DSGE model proposed by Gali (2008). In our study we revisit the provisions made by Gali (2008), portraying them from our perspective. From theoretical perspective, a comprehensive analysis of the basic New Keynesian model and its policy implications can be found in the paper of Walsh (2017). Such model involves three types of agents, namely households, firms and the central bank. It assumes that households own money and bonds, buy consumer goods, and provide labour. Thus, according to the Permanent Income Hypothesis proposed by Milton Friedman, they maximise their consumer utility throughout their entire life cycle (Friedman, 1957). In other words, they maximise their expected utility value. In turn, companies, in order to function efficiently, have to employ staff and, of course, produce and sell diversified products in competitive markets, thereby also trying to maximise their own profits. The third force of the economy is the central bank, which by an implementation of the Taylor rule, are in control of the nominal interest rates, and thus promote a sustainable economy (Woodford, 2001).

The NK DSGE Model can be described by means of six general equilibrium equations (in addition, we introduce three stochastic processes addressing technological, inflationary and monetary policy shocks). All equations are log-linear and contain gap variables. In brief, they can be summarised as follows (more inquisitive readers are referred to Bouda (2014)):

Dynamic IS equation

$$
\tilde{y}_{t}=-\frac{1}{\sigma}\left(i_{t}-E_{t}\left\{\pi_{t+1}\right\}-r_{t}^{n}\right)+E_{t}\left\{\tilde{y}_{t+1}\right\}
$$

New Keynesian Phillips curve (or NKPC for short)

$$
\pi_{t}=\beta E_{t}\left\{\pi_{t+1}\right\}+\kappa \tilde{y}_{t}
$$

Equation addressing the evolution of the natural rate of interest

\footnotetext{
${ }^{7}$ Moreover, housing frictions proved to give better results, despite the fact that the study covered the period of financial turmoil.

${ }^{8}$ The BVAR model is a vector autoregression model which factors in the Bayes Theorem based on prior and posterior distributions.
} 


$$
r_{t}^{n}=\rho+\sigma \psi_{y a}^{n} E_{t}\left\{\Delta a_{t+1}\right\}
$$

Taylor Rule (interest rate rule implemented by the central bank)

$$
i_{t}=\rho+\phi_{\pi} \pi_{t}+\phi_{y} \tilde{y}_{t}+v_{t}
$$

Production function

$y_{t}=a_{t}+(1-\alpha) n_{t}$

Equation reflecting the ad-hoc money demand

$$
m_{t}=\pi_{t}+\tilde{y}_{t}-\eta i_{t}
$$

Due to its limited association with the output in terms of cyclical frequencies, the NK DSGE model does not reflect capital resources. Figure 1 explains the basic structure and dynamics of the NK DSGE model.

\section{Households}

The NK DSGE model proposed by Gali (2008) implies that infinitely-lived households seek to maximise their consumption and labour utility:

$$
E_{0}=\sum_{t=0}^{\infty} \beta^{t} U\left(C_{t}, N_{t}\right)
$$

where $C_{t}$ is the consumption index and $C_{t}(i)$ corresponds to the quantity of the good $i$ consumed by the household during certain period of time $t$. The model assumes the existence of a continuum of goods falling into the interval $[0,1]$.

$$
C_{t}=\left(\int_{0}^{1} C_{t}(i)^{\frac{\varepsilon-1}{\varepsilon}} d i\right)^{\frac{\varepsilon}{\varepsilon-1}}
$$

There is also a budgetary constraint, which may be expressed as follows:

$$
\int_{0}^{1} P_{t}(i) C_{t}(i) d i+Q_{t} B_{t} \leq B_{t-1}+W_{t} N_{t}+T_{t}
$$

where individual variables are defined as follows: $P_{t}(i)$ is the price of a good $i$ and $N_{t}$ represents the hours of work corresponding to the employed members of the household, $W_{t}$ expresses the nominal wages, $B_{t}$ corresponds to the purchases of 1-period bonds at a price $Q_{t}{ }^{9}$, while $T_{t}$ is the lump-sum income component including i.a. transfers and dividends on corporate ownership. There is also made an assumption about the existence of a continuum of goods in the economy. Moreover, households are subject to the following optimisation problem:

$$
\max _{C_{t}(i)} \int_{0}^{1} P_{t}(i) C_{t}(i) d i=P_{t} C_{t}
$$

where the product of the price index times the quantity index ( i.e. $P_{t} C_{t}$ ) expresses the total nominal expenditure on consumption goods. As a next step we need to solve the first order condition given by (10). The conditional extreme of the differential function used in optimisation theory is calculated using the Lagrange method ${ }^{10}$, hence:

\footnotetext{
${ }^{9}$ It is assumed that households hold money and bonds.

${ }^{10}$ The method of Lagrange multipliers is a strategy for finding the local maxima and minima of a function subject to equality constraints.
}

$$
\begin{aligned}
& L=\left[\int_{0}^{1} C_{t}(i)^{\frac{\varepsilon-1}{\varepsilon}} d i\right]^{\frac{\varepsilon}{\varepsilon-1}}-\lambda\left[\int_{0}^{1} P_{t}(i) C_{t}(i) d i-P_{t} C_{t}\right](11 \mathrm{a}) \\
& \frac{\partial L}{\partial C_{t}(i)} \Rightarrow\left[\int_{0}^{1} C_{t}(i)^{\frac{\varepsilon-1}{\varepsilon}} d i\right]^{\frac{1}{\varepsilon-1}} C_{t}(i)^{-\frac{1}{\varepsilon}}=\lambda P_{t}(i) \square C_{t}(i)(11 \mathrm{~b}) \\
& {\left[\int_{0}^{1} C_{t}(i)^{\frac{\varepsilon-1}{\varepsilon}} d i\right]^{\frac{1}{\varepsilon-1}} C_{t}(i)^{\frac{\varepsilon-1}{\varepsilon}}=\lambda P_{t}(i) C_{t}(i) \| \int_{0}^{1} \quad(11 \mathrm{c})} \\
& {\left[\int_{0}^{1} C_{t}(i)^{\frac{\varepsilon-1}{\varepsilon}} d i\right]^{\frac{1}{\varepsilon-1}} \int_{0}^{1} C_{t}(i)^{\frac{\varepsilon-1}{\varepsilon}} d i=\lambda \int_{0}^{1} P_{t}(i) C_{t}(i) d i=\lambda Z_{t}(11 \mathrm{~d})} \\
& {\left[\int_{0}^{1} C_{t}(i)^{\frac{\varepsilon-1}{\varepsilon}} d i\right]^{\frac{1}{\varepsilon-1}} \int_{0}^{1} C_{t}(i)^{\frac{\varepsilon-1}{\varepsilon}} d i=\lambda \int_{0}^{1} P_{t}(i) C_{t}(i) d i=\lambda P_{t} C_{t} \equiv C_{t}(11 \mathrm{e})}
\end{aligned}
$$

where $P_{t} C_{t}$ is the price index multiplied by consumption index, and $\lambda$ is the reciprocal of the price index: $\lambda=\frac{1}{P_{t}}$. Hence, solving the first order condition leads us to derive the formula that represents the demand for a $\operatorname{good} i$ :

$$
\begin{aligned}
& {\left[\int_{0}^{1} C_{t}(i)^{\frac{\varepsilon-1}{\varepsilon}} d i\right]^{\frac{1}{\varepsilon-1}} C_{t}(i)^{-\frac{1}{\varepsilon}}=\frac{P_{t}(i)}{P_{t}}} \\
& C_{t}^{\frac{1}{\varepsilon}} C_{t}(i)=\frac{P_{t}(i)}{P_{t}} \\
& C_{t}(i)=\left(\frac{P_{t}(i)}{P_{t}}\right)^{-\varepsilon} C_{t}
\end{aligned}
$$

Further below we explain how to get a formula for the price index:

$$
\begin{aligned}
& P_{t} C_{t}=\int_{0}^{1} P_{t}(i) C_{t}(i) d i \\
& P_{t} C_{t}=\int_{0}^{1} P_{t}(i)\left(\frac{P_{t}(i)}{P_{t}}\right)^{-\varepsilon} C_{t} d i \\
& P_{t}=\left[\int_{0}^{1} P_{t}(i)^{1-\varepsilon} d i\right]^{\frac{1}{1-\varepsilon}}
\end{aligned}
$$

Plugging the expression (13a) into the budget constraint we arrive at:

$$
\begin{aligned}
& \max _{C_{t}, B_{t}, N_{t}} \sum_{t=0}^{\infty} \beta^{t} U\left(C_{t}, N_{t}\right) \\
& \text { s.t } P_{t} C_{t}+Q_{t} B_{t} \leq B_{t-1}+W_{t} N_{t}+T_{t},
\end{aligned}
$$

where the assumption of the period utility function is expressed as follows:

$$
U\left(C_{t}, N_{t}\right)=\frac{C_{t}^{1-\sigma}}{1-\sigma}-\frac{N_{t}^{1+\varphi}}{1+\varphi},
$$

Consequently, the optimal consumption/savings and labour supply can be expressed as follows:

$$
\begin{aligned}
& \frac{W_{t}}{P_{t}}=C_{t}^{\sigma} N_{t}^{\varphi} \\
& \frac{W_{t}}{P_{t}}=-\frac{U_{n, t}}{U_{c, t}} \\
& Q_{t}=\beta E_{t}\left\{\left(\frac{C_{t+1}}{C_{t}}\right)^{-\sigma} \frac{P_{t}}{P_{t+1}}\right\}
\end{aligned}
$$

The above optimisation conditions have their loglinear equivalents (20-21): 


$$
\begin{aligned}
& w_{t}-p_{t}=\sigma c_{t}+\varphi n_{t} \\
& c_{t}=E_{t}\left(c_{t+1}\right)-\frac{1}{\sigma}\left(i_{t}-E_{t}\left(\pi_{t+1}\right)-\rho\right)
\end{aligned}
$$

where logs of the original variables are denoted with lowercase letters, $i_{t}=-\ln Q_{t}$ is the nominal interest rate, $\rho=-\ln \beta$ is the discount rate and $\pi_{t+1}$ is the rate of inflation between $t$ and $t+1$. The previous conditions are supplemented by an ad-hoc log-linear equation reflecting the demand for money (see eq. 6).

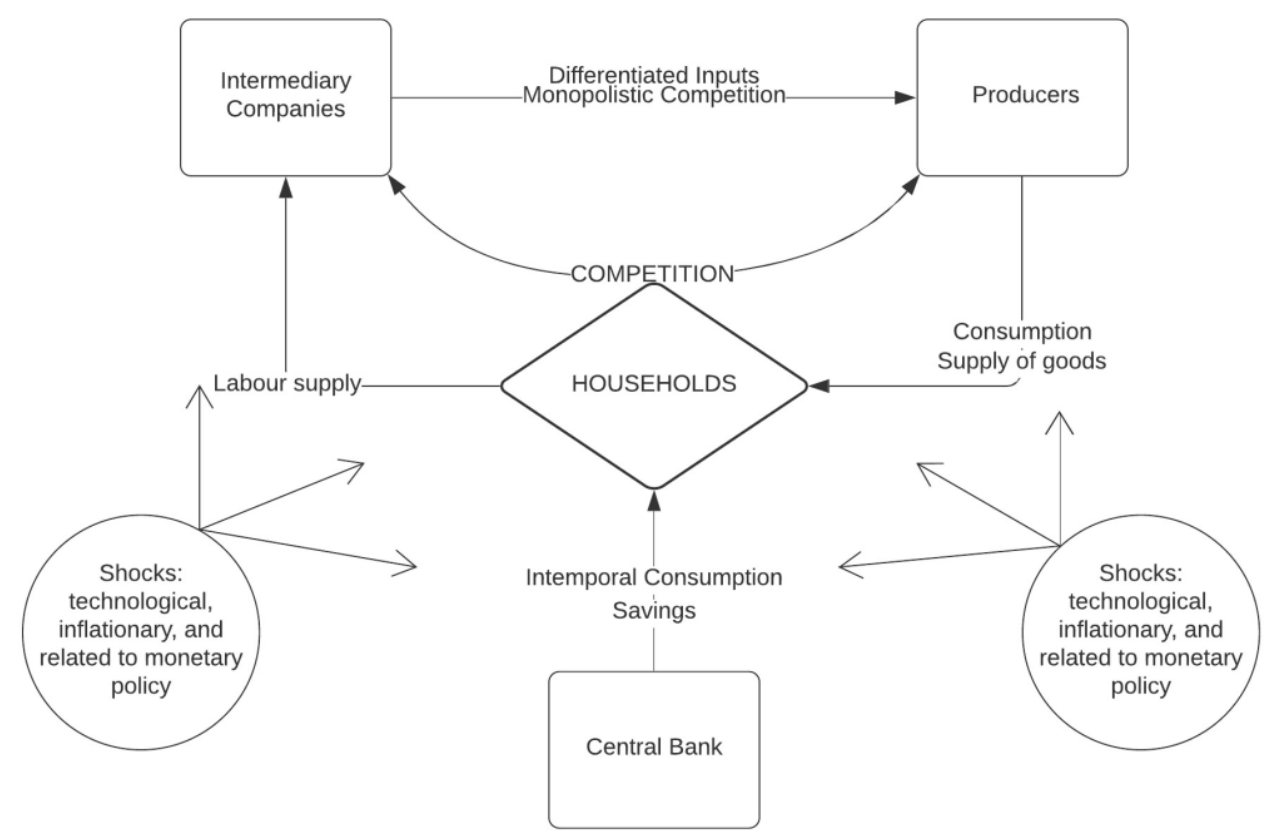

Figure 1. New Keynesian Model

Source: Authors' elaboration

\section{Firms}

The NK DSGE model assumes the existence of a continuum of companies indexed by $i \in[0,1]$. The production of differentiated goods, which is performed by each company, follows the same technology and can be expressed in this way:

$$
Y_{t}(i)=A_{t} N_{t}(i)^{1-\alpha},
$$

where $A_{t}$ expresses the level of the common technology for all companies, and assumes that it evolves exogenously over time. Also, it is assumed that each company is subject to the same demand function, which is characterised by constant elasticity and expressed with the formula:

$$
C_{t}(i)=\left(\frac{P_{t}(i)}{P_{t}}\right)^{-\varepsilon} C_{t},
$$

with aggregate price level index $P$ and aggregated consumption index $C$ as explained above. According to what was proposed by Calvo (1983), in any given time period companies can change their prices with a probability $(1-\theta)$, irrespective of previous adjustments in this respect. Therefore, in any given period a certain proportion of the producers wind up changing their prices, whereas other producers keep their prices at the same level. This allows to determine an average duration of a specific price as $(1-\theta)^{-1}$. Also, $\theta$ represents the natural measure of price stickiness - a situation where the price of a good does not change immediately to a new market- clearing price. Given the foregoing, we can rewrite the equation expressing the aggregate price index dynamics:

$$
P_{t}=\left[\theta\left(P_{t-1}\right)^{1-\varepsilon}+(1-\theta)\left(P_{t}^{*}\right)^{1-\varepsilon}\right]^{\frac{1}{1-\varepsilon}},
$$

where $P_{t}^{*}$ is the price determined in period $t$, by companies reoptimising their prices during that period. The log-linear representation of the aggregated price index reflecting steady state is given by:

$$
\pi_{t}=(1-\theta)\left(p_{t}^{*}-p_{t-1}\right)
$$

Based on the equation (25), there is a direct relationship between the current inflation configuration and the price reoptimisation that companies realise over a given period of time when re-pricing. Therefore, in order to better understand the inflationary processes, it is imperative to look for the causes of companies' decisions resetting their prices. Companies setting the price $P_{t}^{*}$ in period $t$ (thus performing the aforementioned re-optimisation) maximise their current market value of the profits that they generate. From the mathematical notation perspective, a company that optimises its prices solves the following optimisation problem:

$$
\max _{P_{t}^{*}} \sum_{k=0}^{\infty} \Theta^{k} E_{t}\left\{Q_{t, t+k}\left(P_{t}^{*} Y_{t+k / t}\right)-\Psi_{t+k}\left(Y_{t+k / t}\right)\right\}
$$

provided that the demand constraints' sequence is met, which can be expressed as follows:

$$
Y_{t+k / t}=\left(\frac{P_{t}^{*}}{P_{t+k}}\right)^{-\varepsilon} C_{t+k}
$$


where $Q_{t, t+k}$ denotes the stochastic discount factor for nominal payoffs: $Q_{t, t+k}=\beta^{k}\left(C_{t+k} / C_{t}\right)^{-\sigma}\left(P_{t} / P_{t+k}\right), Y_{t+k / t}$ reflects the output in $t$ period, and $\psi_{t+k}\left(Y_{t+k / t}\right)$ is the cost function. The first-order condition that is associated with the optimisation problem described above is given by:

$$
\begin{aligned}
& \sum_{k=0}^{\infty} \theta^{k} E_{t}\left\{Q_{t, t+k} Y_{t+k / t}\left(P_{t}^{*}-M \psi_{t+k}^{\prime}\left(Y_{t+k / t}\right)\right)\right\}=0 \\
& \sum_{k=0}^{\infty} \theta^{k} E_{t}\left\{Q_{t, t+k} Y_{t+k / t}\left(P_{t}^{*}-M \psi_{t+k / t}\right)\right\}=0
\end{aligned}
$$

with $\psi_{t+k / t}=\Psi_{t+k}\left(Y_{t+k / t}\right)$ denoting the marginal cost for the company in period $t+1$ (assuming that such company resets its prices in period $t$ ), and $M=\frac{\varepsilon}{\varepsilon-1}$.

As a next step we linearise the optimal price-setting condition around a zero inflation steady state, and re-write it, dividing it by $P_{t-1}$, assuming that $\Pi_{t, t+k}=P_{t+k} / P_{t}$, which yields:

$$
\sum_{k=0}^{\infty} \theta^{k} E_{t}\left\{Q_{t, t+k} Y_{t+k / t}\left(\frac{P_{t}^{*}}{P_{t-1}}-\mathrm{M} C_{t+k / t} \Pi_{t-1, t+k}\right)\right\}=0
$$

By transforming the above equation (dividing it by $\left.P_{t-1}\right)$, we arrive at its first-order Taylor expansion around the zero inflation steady state:

$$
p_{t}^{*}-p_{t-1}=(1-\beta \theta) \sum_{k=0}^{\infty}(\beta \theta)^{k} E_{t}\left\{m c_{t+k / t}+\left(p_{t+k}-p_{t-1}\right\}\right.
$$

where $m c_{t+k / t}=m c_{t+k / t}-m c$ reflects the deviation (log-linear) of marginal cost from its steady state.

\section{Equilibrium}

The goods market equilibrium can be expressed by the following condition: $Y_{t}(i)=C_{t}(i)^{11}$. Since the aggregate output is given by:

$$
Y_{t}=\left(\int_{0}^{1} Y_{t}(i)^{\frac{\varepsilon-1}{\varepsilon}}\right)^{\frac{\varepsilon}{\varepsilon-1}}
$$

and as a result the $Y_{t}=C_{t}$ condition holds for all $t$. When both conditions (i.e. the market clearing and the Euler consumer's equation) are combined together it yields the equilibrium given by the following formula:

$$
y_{t}=E_{t}\left(y_{t+1}\right)-\frac{1}{\sigma}\left(i_{t}-E_{t}\left(\pi_{t+1}\right)-\rho\right)
$$

The relation between aggregate output, employment, and technology can be expressed as follows:

$$
y_{t}=a_{t}+(1-\alpha) n_{t}
$$

Since it is assumed that companies reoptimise, the marginal cost in period $t$ is reflected as follows:

$$
m c_{t+k / t}=m c_{t+k}-\frac{\alpha \varepsilon}{1-\alpha}\left(p_{t}^{*}-p_{t+k}\right)
$$

After having performed appropriate rearrangements we obtain the following equation for inflation (more inquisitive readers are referred to Gali (2008)):

$$
\pi_{t}=\beta E_{t}\left(\pi_{t+1}\right)+\lambda \hat{m} c_{t}
$$

where: $\lambda=\frac{(1-\theta)(1-\beta \theta)}{\theta} \Theta$, and $\Theta=\frac{1-\alpha}{1-\alpha+\alpha \varepsilon}$

The natural level of output, which is denoted by $y_{t}^{n}$, is defined as a level that provides equilibrium under flexible prices, which can be expressed as follows:

$$
m c=\left(\sigma+\frac{\varphi+\alpha}{1-\alpha}\right) y_{t}^{n}-\frac{1+\varphi}{1-\alpha} a_{t}-\log (1-\alpha)
$$

and implies that:

$y_{t}^{n}=\psi_{y a}^{n} a_{t}+v_{y}^{n}$

where:

$$
v_{y}^{n}=-\frac{(1-\alpha)\left(\log \frac{\varepsilon}{\varepsilon-1}-\log (1-\alpha)\right)}{\sigma(1-\alpha)+\varphi+\alpha}>0,
$$

and

$$
\psi_{y a}^{n}=\frac{1+\varphi}{\sigma(1-\alpha)+\varphi+\alpha} .
$$

Assuming the foregoing conditions the inflation equation can be re-written as follows (i.e. it factors in one period ahead of the inflation forecast and the output gap):

$$
\pi_{t}=\beta E_{t}\left(\pi_{t+1}\right)+\kappa \tilde{y}_{t}+q_{t},
$$

where $_{\kappa}=\lambda\left(\sigma+\frac{\varphi+\alpha}{1-\alpha}\right)$

The above equation (also see eq. 2) is also known as the New Keynesian Phillips curve (NKPC). It forms one of the key elements of the simple New Keynesian DSGE model. Contrary to the classical approach, the NKPC paradigm treats inflation as a non-backward-looking variable and links it to the output gap. The $Q_{t}$ symbol denotes a process that reflects shocks in the inflation rate. Another element of the NK DSGE model is the dynamic IS curve, which is obtained by incorporating the output gap in the expression $y_{t}=E_{t}\left(y_{t+1}\right)-\frac{1}{\sigma}\left(i_{t}-E_{t}\left(\pi_{t+1}\right)-\rho\right)$ :

$$
\left.\tilde{y}_{t}=-\frac{1}{\sigma}\left(i_{t}-E_{t}\left(\pi_{t+1}\right)-r_{t}^{n}\right)+E_{t}\left(\tilde{y}_{t+1}\right), \quad \text { (see eq. } 1\right)
$$

where $r_{t}^{n}$ denotes the natural interest rate and is expressed as follows:

$$
r_{t}^{n}=\rho+\sigma \psi_{y a}^{n} E_{t}\left(\Delta a_{t+1}\right)
$$

The model also contemplates the monetary policy, which is represented by the simple Taylor rule (see eq. 4). The last three equations represent stochastic shocks which can be perceived as 3 exogenous variables $\left(a_{t}, v_{t}, q_{t}\right)$ that follow the $\operatorname{AR}(1)$ autoregressive process and capture the shocks to technology, inflation and short-term interest rates:

$$
\begin{aligned}
& a_{t}=\rho_{a} a_{t-1}+\varepsilon_{a} \\
& v_{t}=\rho_{v} v_{t-1}+\varepsilon_{v} \\
& q_{t}=\rho_{q} q_{t-1}+\varepsilon_{q}
\end{aligned}
$$

where $\varepsilon_{a}, \varepsilon_{v}, \varepsilon_{q}, \sim W N\left(0, \sigma^{2}\right)$ are independent and identically distributed random variables (i.e. white noise), that are uncorrelated with $a_{t-1}, v_{t-1}, q_{t-1}$, with zero mean and standard deviations $\sigma_{a}, \sigma_{v}, \sigma_{q}$, respectively.

\footnotetext{
${ }^{11}$ The goods market reaches equilibrium under the following condition.
} 


\section{Data and Methodology}

All the data were obtained from OECD and EUROSTAT ${ }^{12}$ databases. We use quarterly time series for the following variables: Real GDP [EUROSTAT], Consumer Price index [DATA.OECD], Short term nominal interest rate (3 month) [DATA.OECD]. The data covers the period between 2000Q1 and 2019Q4, which makes 80 quarterly observations for each variable.

The real gross domestic product constitutes the inflation adjusted value of the goods and services generated by labor and property located in Poland. Inflation is measured by the consumer price index (CPI) and is defined as the change in the prices of a basket of goods and services that are typically purchased by specific groups of households. It is expressed in terms of the annual growth rate and in index 2015 base year with a breakdown for food, energy and total excluding food and energy (OECD, 2020). In turn, short-term interest rates are the rates at which short-term borrowings are effected between financial institutions or the rates at which shortterm government paper is issued or traded in the market ${ }^{13}$. Short-term interest rates are averages of daily rates, measured as a percentage and they are based on threemonth money market rates.

To fit the model the raw data $\left(r_{-} o b s\right)$ extracted from both the Federal Reserve Economic Data (FRED) and OECD databases were transformed accordingly. In order to match the model variables, the data were transformed as follows:

1. Inflation - we take the first difference of logs of the Harmonised Indices of Consumer Prices (HICP) and then we demean them ${ }^{14}$.

2. Interest rate - r_obs $=\log \left(1+r \_\right.$data/400) - mean ( $\log \left(1+r \_ \text {data/400) }\right)^{15}$

3. GDP - we log-transform the data and detrend it with one-sided HP filter ${ }^{16}$.

The next step is to estimate the stationary cyclical component for the real GDP, which can quite well be described with the use of the stochastic processes. We do this with the Hodrick-Prescott (HP) filter. It can be mathematically expressed as the difference between $\tau_{t}=y_{t}-c_{t}$, where $\tau_{t}$ is the trend component and $c_{t}$, is the cyclical component. That is how we derive the trend component. Economists often use the HP high pass-filter as a general method for time series analysis, although there are also some critics of this method (Hamilton, 2017). Hodrick and Prescott (1997) proposed the HP high pass filter as a trend-removal technique that can be applied to a wide range of data generation processes. It allows for determining a trend and filtering

\footnotetext{
${ }^{12}$ Technically, the data was extracted from the FRED database, though the real source is EUROSTAT.

${ }^{13}$ This definition is taken from the official OECD webpage.

${ }^{14} \pi_{t}^{\text {data }}=\log \left(\frac{C P I_{t}}{C P I_{t-1}}\right)-\log \left(\operatorname{mean}\left(\frac{C P I_{t}}{C P I_{t-1}}\right)\right)=\pi_{t}$

${ }^{15} i_{t}^{\text {data }}=\log \left(1+\frac{i_{t}^{\text {data }}}{400}\right)-$ mean $\left(\log \left(1+\frac{i_{t}^{\text {data }}}{400}\right)\right)=i_{t}$

${ }^{16} y_{t}^{\text {data }}=\log \left(y_{t}^{\text {data }}\right)-\log \left(y_{t}^{\text {trend }}\right)=\tilde{y}_{t}$
}

the data so as to detrend it. The smoothness of the trend depends on the $\lambda$ parameter. The higher the $\lambda$ the smoother the trend. For quarterly data Hodrick and Prescott (1997) recommended setting $\lambda$ to 1600 . Raw data (Figure 2) and the processed data used in the model are illustrated below in Figure 3.

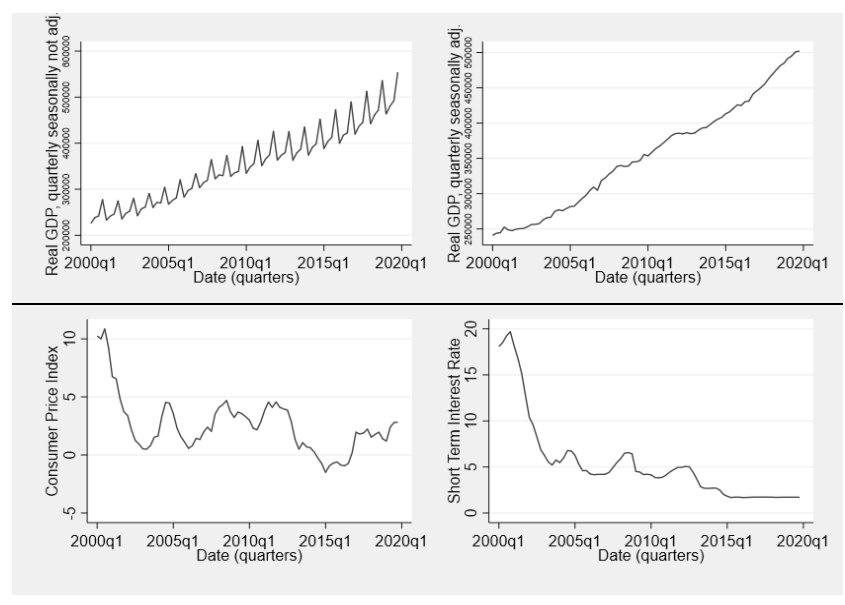

Figure 2. Raw Data Extracted from Different Sources Source: Authors' elaboration

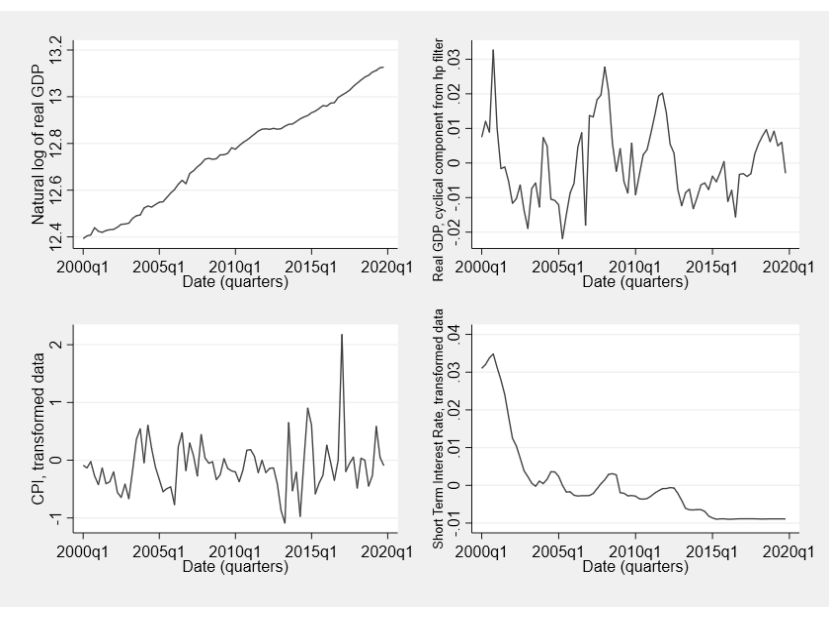

Figure 3. Transformed Data Employed in the Model

Source: Authors' elaboration

In Bayesian statistical inference, a prior probability distribution (or Priors for short) is the probability distribution that reflect one's beliefs about some parameters included in the model before even the actual evidence is taken into account. Prior distributions play an important role in estimating DSGE models (Smets \& Wouters, 2003). They can be obtained from individual introspection in order to reflect the well-established understanding of the validity of some economic theories; in practice, most priors are chosen on the basis of certain observations (An, Schorfheide, 2007).

The assumptions with regards to parameters and calibration values for our model are primarily derived from studies on Polish economy (Grabek et al. 2007; Kolasa, 2009). In few cases small corrections were required based on Brzoza-Brzezina et al. (2013) and Wesolowski (2018). We assume that the conventional discount factor $(\beta)$ is equal to 0.99 , which implies an annual interest rate of $1 \%$ 
(for a sustainable economy), or about four per cent expressed at an annual frequency, which is a common value in the literature (Wesolowski, 2018). Coupled with the steady state inflation of 0.01 , it implies that the steady state nominal interest rate is about 0.02. In turn, the characteristics of the technological shock are similar to those found in Prescott (1986), i.e. the autoregressive parameter is equal to 0.95 . Moreover, we set the elasticity of substitution $n$ to 6 , labor elasticity $\phi$ to 1 , capital share $\alpha$ to 0.43 (according to the World Bank database the capital share in Poland equals $0,43 \%) ; \sigma$ is set to 1 , implying a log utility function, and the elasticity of money demand $\eta$ is set to 4 (for explanation more inquisitive readers are referred to Wesolowski (2018)). For sticky price parameter $(\theta)$ we select a Beta distribution with the mean equal to 0.7 and standard deviation of 0.1 .

Table 1

The Calibration of all Structural Parameters

\begin{tabular}{|c|c|c|}
\hline Parameter & Description & Prior \\
\hline$\alpha$ & share of capital & 0.43 (World Bank) \\
\hline$\beta$ & discount factor & 0.99 \\
\hline$\varepsilon$ & elasticity of substitution & 6 \\
\hline$\theta$ & price stickiness & $\begin{array}{c}0.7 \\
\text { (Wesolowski, 2018) } \\
\end{array}$ \\
\hline$\rho$ & $\begin{array}{l}\text { real interest rate in the } \\
\text { steady state }\end{array}$ & $-\log ($ lbeta $)=1 \%$ \\
\hline$\sigma$ & $\begin{array}{l}\text { coefficient of risk } \\
\text { aversion }\end{array}$ & 1 \\
\hline$\phi$ & elasticity of labor supply & 1 \\
\hline$\phi_{\pi}$ & $\begin{array}{l}\text { sensitivity of the central } \\
\text { bank with respect to the } \\
\text { inflation }\end{array}$ & $\begin{array}{c}2.00 \\
\text { (Wesolowski, 2018) }\end{array}$ \\
\hline$\phi_{y}$ & $\begin{array}{l}\text { sensitivity of the central } \\
\text { bank with respect to the } \\
\text { output gap }\end{array}$ & $\begin{array}{c}0.5 \\
\text { (Wesolowski, 2018) }\end{array}$ \\
\hline$\rho_{a}$ & $\begin{array}{l}\text { persistence of the } \\
\text { technology shock }\end{array}$ & 0.75 \\
\hline$\rho_{v}$ & $\begin{array}{l}\text { persistence of the } \\
\text { monetary policy shock }\end{array}$ & 0.25 \\
\hline$\rho_{q}$ & $\begin{array}{l}\text { persistence of the } \\
\text { inflation shock }\end{array}$ & 0.75 \\
\hline$\rho_{q}$ & $\begin{array}{l}\text { persistence of the } \\
\text { inflationary shock }\end{array}$ & 0.75 \\
\hline$\eta$ & $\begin{array}{l}\text { elasticity of money } \\
\text { demand }\end{array}$ & 4 \\
\hline
\end{tabular}

Source: adapted Grabek et al. (2007); Kolasa (2009); Bouda (2014); Wesolowski (2018)

Furthermore, we find a relatively strong domestic price stickiness (Calvo parameters) in the data reflecting strong inflation persistence (Wesolowski, 2018). The estimated Calvo parameters are in line with the micro study for Poland (Macias \& Makarski 2013). The inflation feedback Taylor Rule $\left(\phi_{p i}\right)$ is best reflected with the normal distribution with an average of 2.0 and standard deviation of 0.5 , while the output feedback Taylor Rule $\left(\phi_{y}\right)$ is best reflected in the Beta distribution with an average of 0.5 and standard deviation of 0.01 (Wesolowski, 2018). In the case of autoregressive parameters for technological and inflationary shocks, we select the Beta distributions with averages equal to 0.75 and standard deviations of 0.1 . For the parameter "persistence of the monetary shock" $\left(\rho_{v}\right)$, we take the average that is equal to 0.25 and the standard deviation of 0.1. Exogenous processes are best described by Inverse Gamma distributions with means that are equal to 0.05 and standard deviations of 4 (Bouda, 2014). To perform the Bayesian estimation we use the DYNARE 4.6.1.software with a comprehensive package that features with built-in Bayesian techniques so as to estimate the models. The Bayesian techniques are quite well illustrated in Koop's paper (2003) and the DSGE model estimation process itself is described in detail by FernandezVillaverde's (2010). In turn, DSGE models developed in DYNARE 4.6.1 are thoroughly explained in Barillas et al. (2010). When calibrating a model with the use of Bayesian techniques relying on conditional probabilities, the aim is to find posterior distributions of all parameters estimated from the observed data. These distributions are obtained by taking the initial distributions of the parameters and using the probability functions, which in turn are based on Kalman filters. The generation of posterior distributions is based on the Metropolis-Hastings method, which involves a specific proposal distribution in which a variable from the system is drawn conditionally on the basis of all other variables. In essence, the Metropolis-Hastings (MH) algorithm can use any form of proposal distribution that depends on the current sample.

\section{Results}

Our model assumes 30,000 draws with the use of the Metropolis-Hastings random walk method (Brooks, Gelman, 1998). This is a relatively small number, and the procedure of determining the relevant parameter values took a relatively long time (one and a half hours), which means that the estimates passed all the usual convergence tests and seem to be stable. Subsequent medians and values of the 90 per cent highest posterior density (HPD) interval of the estimated model parameters are shown in Table 3. Figure 1 shows the distribution of each parameter. The Metropolis-Hastings diagnostic tests proposed by Brooks and Gelman (1998) reflect the overall and single-factor convergence of the estimated values in the MH chains, and allow to assess the stability of the results. The convergence of these series for the estimation of our model proves to be satisfactory. Set out below are the prior and posterior distributions, and the convergence tests (see Table $2 \& 3$ ).

Table 2

\section{Prior Distributions}

\begin{tabular}{|c|c|c|c|c|}
\hline Parameter & Distribution & Mean & Mode & Std.Dev. \\
\hline$\theta$ & Beta & 0.700 & 0.7002 & 0.0081 \\
\hline$\phi_{p i}$ & Normal & 2.000 & 1.6030 & 0.0581 \\
\hline$\phi_{y}$ & Beta & 0.500 & 0.4999 & 0.0094 \\
\hline$\rho_{a}$ & Beta & 0.750 & 0.8465 & 0.0394 \\
\hline$\rho_{v}$ & Beta & 0.250 & 0.0603 & 0.0317 \\
\hline$\rho_{q}$ & Beta & 0.750 & 0.6142 & 0.0735 \\
\hline$\sigma_{a}$ & Inv. Gamma & 0.050 & 0.0255 & 4.0000 \\
\hline$\sigma_{v}$ & Inv. Gamma & 0.050 & 0.7211 & 4.0000 \\
\hline$\sigma_{q}$ & Inv. Gamma & 0.050 & 0.2122 & 4.0000 \\
\hline
\end{tabular}

Source: Authors' elaboration 
Table 3

Posterior Distributions

\begin{tabular}{|c|c|c|c|c|c|c|}
\hline 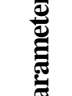 & $\begin{array}{l}\text { Prior } \\
\text { mean }\end{array}$ & $\begin{array}{l}\text { Post. } \\
\text { mean }\end{array}$ & \multicolumn{2}{|c|}{$\begin{array}{l}90 \% \text { HPD } \\
\text { interval }\end{array}$} & $\begin{array}{l}\text { Prior } \\
\text { dist. }\end{array}$ & $\begin{array}{l}\text { Prior } \\
\text { Std. }\end{array}$ \\
\hline$\theta$ & 0.700 & 0.7001 & 0.6845 & 0.7162 & beta & 0.0100 \\
\hline$\phi_{p i}$ & 2.000 & 1.6412 & 1.5339 & 1.7375 & normal & 0.5000 \\
\hline$\phi_{v}$ & 0.500 & 0.5010 & 0.4855 & 0.5160 & beta & 0.0100 \\
\hline$\rho_{a}$ & 0.750 & 0.8549 & 0.7904 & 0.9317 & beta & 0.1000 \\
\hline$\rho_{v}$ & 0.250 & 0.0794 & 0.0207 & 0.1439 & beta & 0.1000 \\
\hline$\rho_{q}$ & 0.750 & 0.6129 & 0.4568 & 0.7727 & beta & 0.1000 \\
\hline$\sigma_{a}$ & 0.050 & 0.0297 & 0.0176 & 0.0423 & invg & 4.0000 \\
\hline$\sigma_{v}$ & 0.050 & 0.7471 & 0.6378 & 0.8484 & invg & 4.0000 \\
\hline$\sigma_{q}$ & 0.050 & 0.2162 & 0.1513 & 0.2787 & invg & 4.0000 \\
\hline
\end{tabular}

Source: Authors' elaboration

Table 3 shows estimates of the parameters. The lack of large differences between prior and posterior values may indicate a good selection of the model input parameters. Moreover, the width of the confidence intervals also finds its interpretation. If it is too wide-ranging, it may be due to, for example, a short time frame of data, and usually indicates a lack of statistical significance of the obtained results. A high $\phi_{p i}$ ratio can be interpreted in terms of the central bank's greater sensitivity to inflationary shocks. It satisfies the Taylor rule since it implies that in the event of a sustained increase in the inflation rate by $k$ per cent, the nominal interest rate will eventually be raised by more than $k$ per cent $\left(\phi_{p i}>1\right)$. In turn, a low $\phi_{y}$ indicator can be regarded as a small sensitivity of the central bank to the output gap ( $\phi_{p i}$ is relevantly lower that 1 ). Since the share of capital is equal 0.43 , the share of labour is 0.57 (i.e. 1 share of capital). It is worth noting that the share of labour for Polish economy has been systematically declining since the beginning of the transformation which took place about 30 years ago. For example, in the year 2000 it oscillated between $0.65-0.66$. This type of indicator can be used e.g. for macroeconomic forecasts of total factor productivity (TFP), with the use of the Cobb-Douglas function.
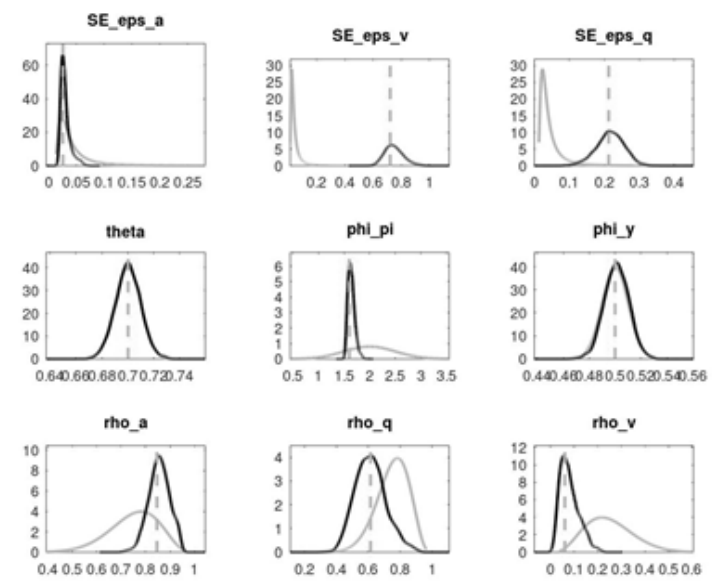

Figure 4. Posterior Distributions
Table 3 provides the priors together with the posterior distributions and their averages. From the posterior distribution of the Calvo $(\theta)$ parameter it is possible to determine the average duration of prices in the economy. The model estimated for the Polish macro data indicates that this parameter is 0.7001 . It shows the average duration between price changes. Assuming price re-setting in a current period, we can therefore ask what is the expected duration until the next price change? The probability of price changes in the subsequent period is equal to $1-\theta$. The probability of price changes in two periods is $1-\theta$ multiplied by the probability that there is no price change after one period, or $(1=\theta) * \theta$. On the other hand, the probability that prices will remain stable within three periods is $(1-\theta)$ multiplied by the probability of not changing prices in two consecutive periods, or $(1-\theta) * \theta^{2}$. Hence, the probability of price changes after 3-month period equals 0,2999 (or 29,99\%). Again, a measure of the price stickiness equal to zero would be interpreted as "total price elasticity". Thus, the probability of a change in prices between quarters would be 100 per cent. The higher the measure the less elastic are the prices. For example, Christiano et al. (2005) assume in their study that $\theta$ parameter is equal to 0.60 , with a standard error of 0.08 . In turn, Eichenbaum and Fisher (2005) estimated $\theta$ parameter with a reasonable precision ranging from 0.83 to 0.89. Furthermore, Wesolowski (2018) found a relatively strong domestic price stickiness (i.e. high Calvo parameters) in the data, meaning that it reflects strong inflation persistence (Wesolowski, 2018). Moreover, the estimated Calvo parameters are in line with the micro study for Poland (Macias \& Makarski, 2013). In turn, $\hat{\phi}_{\pi}=1.6412$ indicates what kind of a reaction we can expect from the central bank in case of a deviation of the inflation from its steady state (the higher the value of this parameter, the quicker would be the response of the central bank; in this case the reaction is faster than average). In contrast, the low value of the parameter $\hat{\phi}$ indicates a slight reaction to the output gap $\left(\hat{\phi}_{y}=0.5010\right)$. With regards to shock processes $\operatorname{AR}(1)$ and the parameters $\rho$, persistence of the effects of such processes is dependent on the value of these parameters (the higher the value of the parameter the longer persist the effects of such processes). Our results show that the technological shock is the most persistent (with the AR (1) coefficient equal to 0.8549), which seems to be quite understandable; the second longest lasting impact comes from the inflation shock (coefficient equal to 0.4568), and the least persistent is the impact associated with monetary policy decisions (0.0794). The model describes the dynamics of macro data for the Polish economy relatively well. In order to understand the evolution process of the macroeconomic variables included in the model, we examine the impulse responses to orthogonalised shocks - technological, inflationary, and the one related to monetary policy. The impulse responses (with the Bayesian $90 \%$ HPD intervals, are shown in Figure 5-7). 

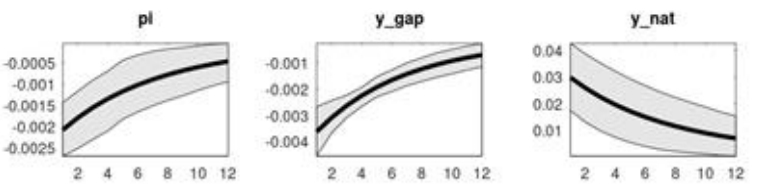

y
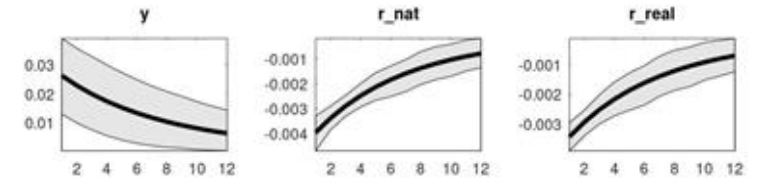

n
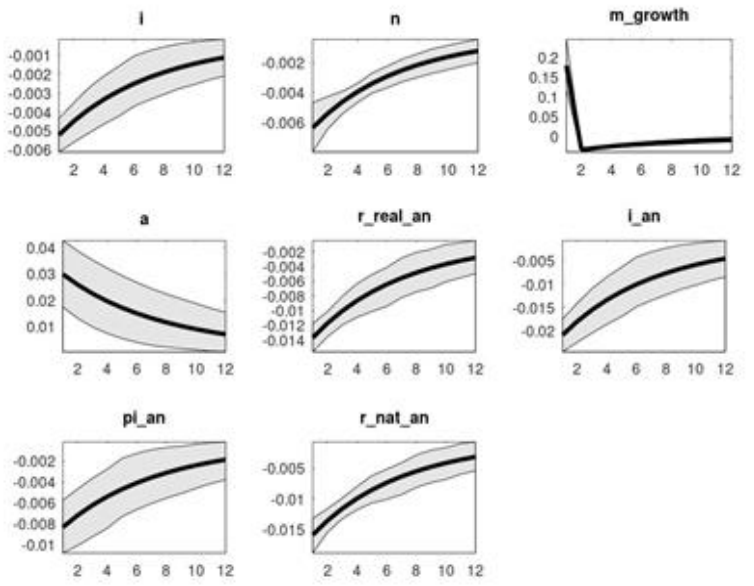

Figure 5. Impulse Response to Orthogonalised Shock to Technology Source: Authors' elaboration
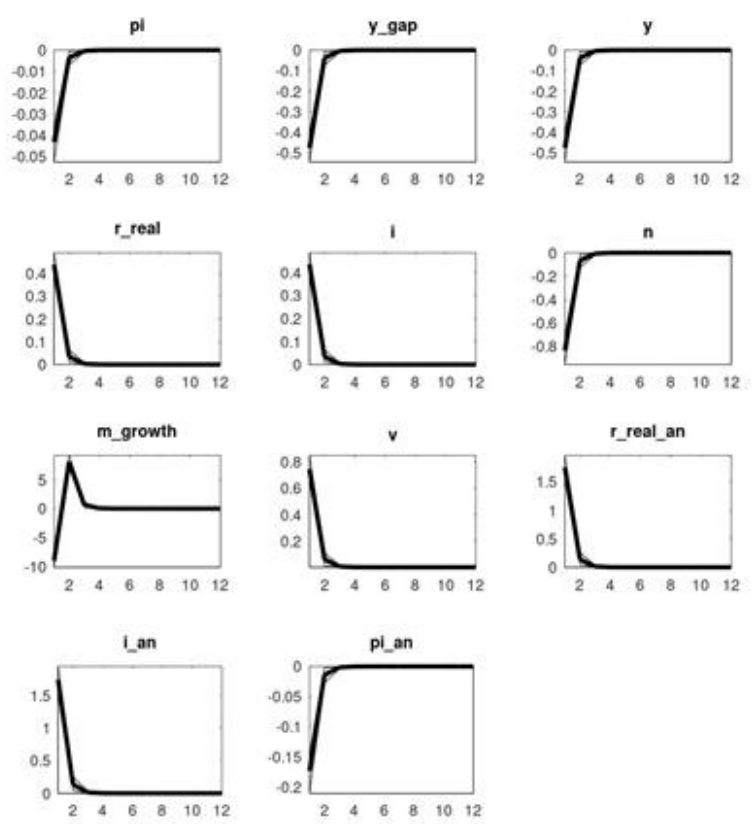

Figure 6. Impulse Response to Orthogonalised Shock to Monetary Policy

Source: Authors' elaboration

It is worth noting that the width of the confidence intervals indicates the reliability of the obtained results. For example, a response to a monetary policy shock (Figure 6 above) could be interpreted as an increase in the interest rate by 74.71 basis points.
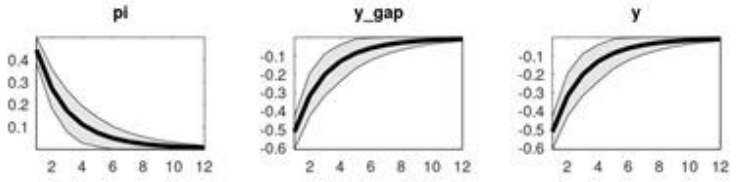

treal
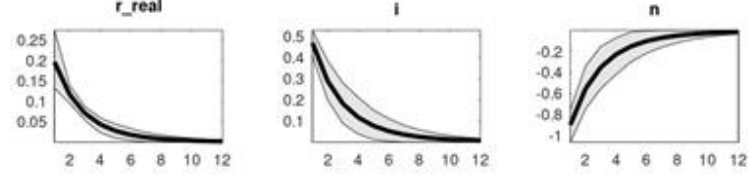

m_growth

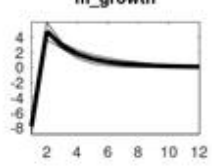

q
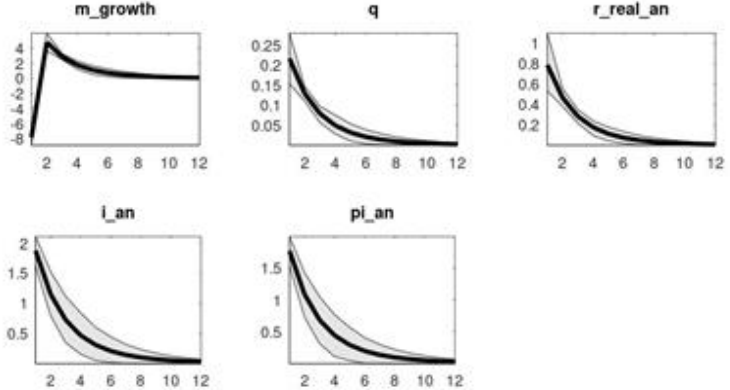

Figure 7. Impulse Response to Orthogonalised Shock to Inflation

Source: Authors' elaboration

Also, an exogenous interest rate increase is associated with persisting output gap and inflation trends ${ }^{17}$. In turn, the output gap itself affects production and has no apparent linkage to monetary policy. Furthermore, both the output gap and inflation depend on the interest rate, in that exogenous rise of the latter usually leads to a permanent decrease in inflation and an even smaller output gap. At the same time, the central bank influences the money supply M2 (i.e. creating the liquidity effect) through its interest rate decisions. The shock that accompanies the monetary policy also exerts an influence on the employment level. Responses to a positive technological shock (shown in Figure 5) indicate a sustained decline in inflation and the output gap. A greater increase in the natural level of output in relation to actual output leads to a decrease in the output gap. In such a situation the central bank cuts interest rates (nominal and real), and thereby increases the money supply. The technological shock contributes to a decrease in the natural level of interest rates and employment. In Figure 7 we can see the function of the impulse response to inflation shock. Since the objective and responsibility of the central bank is to maintain the stability prices (and not necessarily the actual output at a level exceeding its natural equivalent), the central bank primarily seeks to increase interest rates and to reduce the money supply. However, it is a double-edged sword, since such an increase in interest rates, although it allows for fighting inflation, on the other hand, it contributes to the reduction in the actual output level and leads to a further decrease in employment.

\section{Conclusions}

For the purposes of this paper we have estimated the New Keynesian DSGE Model for the Polish economy taking into account full quarterly data from the last two decades. The model is developed with the use of the

\footnotetext{
${ }^{17}$ Natural output levels do not respond to monetary policy shocks.
} 
Bayesian techniques. Generally, the NK DSGE model allows to formulate a perception of some macroeconomic fundamentals, e.g. nominal interest rates, inflation and the output gap. In other words, it provides a better understanding of the relationship between interest rates, inflation and the output gap. This in turn makes it easier to understand the monetary policy function of the central bank. The usefulness and practicality of DSGE models results from their structural nature and the fact that they allow for the implementation of different policy paths and, consequently, provide estimates of macroeconomic forecasts. Also, DSGE models facilitate the analysis of the structural sources of forecasting errors. Also, the NK DSGE model is particularly well suited for making comparisons between actual and implied data for such economic measures as the output gap, inflation and interest rates. A model such as the one presented in this paper also serves for forecasting future economic numbers. The estimation of individual parameters of the model allows us to provide an overview of such economic processes as, for example, the average duration of prices which is illustrated by the Calvo parameter. Moreover, with this paper we also show in a simple way the impulse-responses to the subsequent shocks, i.e. technological, inflationary and the one related to monetary policy. By means of the NK DSGE model we have determined the parameters of the monetary rule, explaining the reaction of the central bank to inflation shock and the output gap. Another conclusion is that although the central bank responds to inflation shocks through its monetary policy, it comes at the expense of a negative output gap, i.e. meaning that the burden of counteracting inflationary trends is borne by the companies. The NK DSGE model also makes it easier to perceive the economy through the prism of relevant quantitative measures. For example, it can be used to forecast GDP and output gaps. However, it must also be kept in mind that this type of models has a theoretical dimension, and therefore it can be estimated in a much more complex form, taking into account various additional parameters, e.g. financial frictions, or even housing frictions (Kolasa \& Rubaszek, 2015).

On the other hand, the DSGE models were criticised by several authors, mostly for "the analysis of stationary fluctuations at business cycle frequencies" (Korinek, 2017; Stiglitz, 2018; Pollitt, 2020). However, none of the critics has offered any constructive advice as to how to deal with non-stationary data (Christiano et al., 2018; Hendry \& Muellbauer, 2018). Moreover, it is impossible not to notice that the development of DSGE models is evolutionary in its nature, meaning that it takes the form of a continuous improvement of the baseline models, equipping them with new functions, which is often inspired by prior criticism. They represent an organic process, which takes place at the point of contact between criticism, some theoretical considerations, but also the available data. Typically, new DSGE models factor in some new assumptions, resulting from the critical dissection of the weak points of the prior models, which is precisely due to their confrontation with the reality (e.g., financial crises, some binary events like COVID-19, etc.) as well as the constructive criticism (Bekiros \& Paccagnini, 2014; Korinek, 2017; Stiglitz, 2018; Pollitt, 2020). Thus, the post-crisis DSGE models have filled some gaps, revealed by the financial crisis and its consequences, e.g. by including financial frictions, housing frictions, and heterogeneity. There is also a need to take into account some deviations from conventional rational expectations, e.g. $k$-level thinking, social learning, robust control, adaptive learning and finally the relaxation of commonknowledge assumptions (Christiano et al., 2018; Hendry \& Muellbauer, 2018). More importantly, some of the underlying DSGE models (such as the one that we have presented in this paper) can be viewed in light of some theoretical systems of assumptions, concepts and interdependencies that allow describing (as well as modelling and forecasting) the approximation of the economic reality. These theoretical constructs are then organically equipped with certain additional functions, such as friction, heterogeneity, certain deviations from conventional rational expectations, etc. Today it is difficult to predict into which direction the further development of DSGE models will go. Addressing the criticism expressed by e.g. Pollitt (2020), it is also hard to expect that any models (not necessarily DSGE) will ever have the capacity to anticipate the timing of future crises, and in particular the binary event-type ones such as the COVID-19 crisis. This is because we are not able to predict everything and be prepared for every eventuality, especially when some kind of binary events come into play. The current crisis is the best proof of this. In fact, people who spend their whole lives in pursuit of the holy grail of models which will allow them to predict the future with an utmost accuracy, or policymakers who try to prevent such crises at all costs, seem to forget Milton Friedman's words that only a crisis - actual or perceived - produces real change. When that crisis occurs, the actions that are taken depend on the ideas that are lying around. That is our basic function: to develop alternatives to existing policies, to keep them alive and available until the politically impossible becomes the politically inevitable (Friedman, 2020). In other words, crises are necessary and inevitable. They form part of the normal economic cycle in capitalist societies.

Despite the sharp criticism DSGE models still remain an important tool in the hands of serious financial institutions. For example, the National Bank of Poland (NBP) uses them for forecasting the exchange rate (Ca'Zorzi et al. 2017). Apart from everything, each crisis has different causes, e.g. the financial crisis of 2008-2009 was caused by the boom in the US mortgage loans that banks in the United States provided to people with insufficient financial capacity, which was associated with a high risk of repayment (a.k.a. the subprime mortgage crisis). The cause of the current crisis is the coronavirus epidemic, the evolution and effects of which depend on the decisions of politicians and policymakers, but also on the behaviour of hundreds of thousands of people around the world.

In the context of the foregoing, it is not important to pay so much attention to the fact that DSGE models fail to accurately predict the state of the economy. Rather, we are supposed to regard them as a certain guidance, which allows us to better understand the economy.

To sum up, DSGE modeling allows for a clear assessment and identification of structural shocks and 
structural parameters. Moreover, they are used at central banks and academia (usualy somewhat extended). They offer several attractive applications, e.g. historical decompositions (every endogenous variable can be decomposed into effects of past shocks), forecasting, couterfactual simulations, optimal policy, rules vs. discretion, etc. For example, they can be used to simulate different policies. More specifically, there are two possible types of counterfactual simulations, which either address the changes with regards to some shocks in the past or the changes of past policies. Also, unlike in the case of VAR models, all shocks in a DSGE model can have an economic interpretation. Furthermore, they can be used for forecasting purposes so as to make assumptions about plausible shocks in the future. In a particular case they can be used to forecast GDP growth.

\section{References}

Adolfson, M., Linde, J., \& Villani, M. (2007). Forecasting performance of an open economy DSGE model. Econometric Reviews, 26(2/4), 289-328. https://doi.org/10.1080/07474930701220543

An, S., \& Schorfheide, F. (2007). Bayesian analysis of DSGE models. Econometric reviews, 26(2/4), 113-172. https://doi.org/10.1080/07474930701220071

Barillas, F., Bhandari, A., Colacito, R., Kitao, S., Deptartment, F. B. E., Matthes, C., \& Shin, Y. (2010). Practicing dynare. mimeo, New York University.

Bekiros, S. D., \& Paccagnini, A. (2014). Bayesian forecasting with small and medium scale factor-augmented vector autoregressive DSGE models. Computational statistics \& data analysis, 71, $298-323$. https://doi.org/10.1016/j.csda.2013.09.018

Bernanke, B. S., Gertler, M., \& Gilchrist, S. (1999). The financial accelerator in a quantitative business cycle framework. Handbook of macroeconomics, 1, 1341-1393. https://doi.org/10.1016/S1574-0048(99)10034-X

Bouda, M. (2014). Econometric Models and their ability to predict GDP growth of the Czech Republic. AAK-Acta academica karviniensia, 14(3), 5-14. https://doi.org/10.25142/aak.2014.043

Brooks, S. P., \& Gelman, A. (1998). General methods for monitoring convergence of iterative simulations. Journal of computational and graphical statistics, 7(4), 434-455. https://doi.org/10.1080/10618600.1998.10474787

Brzoza-Brzezina, M., Kolasa, M., \& Makarski, K. (2013). The anatomy of standard DSGE models with financial frictions. Journal of Economic Dynamics and Control, 37(1), 32-51. https://doi.org/10.1016/j.jedc.2012.06.008

Calvo, G. A. (1983). Staggered prices in a utility-maximizing framework. Journal of monetary Economics, 12(3), 383398. https://doi.org/10.1016/0304-3932(83)90060-0

Ca'Zorzi, M., Kolasa, M., \& Rubaszek, M. (2017). Exchange rate forecasting with DSGE models. Journal of International Economics, 107, 127-146. https://doi.org/10.1016/j.jinteco.2017.03.011

Christiano, L. J., Eichenbaum, M., \& Evans, C. L. (2005). Nominal rigidities and the dynamic effects of a shock to monetary policy. Journal of political Economy, 113(1), 1-45. https://doi.org/10.1086/426038

Christiano, L. J., Motto, R., \& Rostagno, M. (2010). Financial factors in economic fluctuations, ECB Working Paper No. 1192. https://ssrn.com/abstract $=1600166$

Christiano, L. J., Eichenbaum, M. S., \& Trabandt, M. (2018). On DSGE models. Journal of Economic Perspectives, 32(3), 113-40. https://doi.org/10.1257/jep.32.3.113

Curdia, V., \& Woodford, M. (2016). Credit frictions and optimal monetary policy. Journal of Monetary Economics, 84, 30-65. https://doi.org/10.1016/j.jmoneco.2016.10.003

Del Negro, M., \& Schorfheide, F. (2013). DSGE model-based forecasting. In Handbook of economic forecasting (Vol. 2, pp. 57-140). Elsevier. https://doi.org/10.1016/B978-0-444-53683-9.00002-5

Eichenbaum, M., \& Fisher, J. (2005). Evaluating Calvo-Style Sticky Price Models. Federal Reserve Bank of Chicago. Unpublished manuscript. https://doi.org/10.3386/w10617

Farmer, R. E. (1991). The Lucas Critique, policy invariance and multiple equilibria. The Review of Economic Studies, 58(2), 321-332. https://doi.org/10.2307/2297970

Friedman, M. (1957). A Theory of the Consumption Function number frie57-1. In 'NBER Books.'. https://doi.org/10.1515/9780691188485

Friedman, M. (2020). Capitalism and freedom. University of Chicago press.

Gali, J. (2008). Monetary Policy and the Open Economy. Monetary Policy, Inflation, and the Business Cycle: An Introduction to the New Keynesian Framework.

Gertler, M., \& Karadi, P. (2011). A model of unconventional monetary policy. Journal of monetary Economics, 58(1), 1734. https://doi.org/10.1016/j.jmoneco.2010.10.004

Ghent, A. C. (2009). Comparing DSGE-VAR forecasting models: How big are the differences?. Journal of Economic Dynamics and Control, 33(4), 864-882. https://doi.org/10.1016/j.jedc.2008.10.004 
Grabek, G., Klos, B., \& Utzig-Lenarczyk, G. (2007). SOE-PL-model DSGE malej otwartej gospodarki estymowany na danych polskich: metodologia, specyfikacja, wyniki estymacji i pierwsze zastosowania. Narodowy Bank Polski. Departament Komunikacji Spolecznej.

Hamilton, J. (2017). Why you should never use the Hodrick-Prescott filter. Available from internet: https://voxeu.org/article/why-you-should-never-use-hodrick-prescott-filter, $\quad$ May 25, 2020. https://doi.org/ $10.3386 / w 23429$

Hansen, G. D. (1985). Indivisible labor and the business cycle. Journal of monetary Economics, 16(3), 309-327. https://core.ac.uk/reader/190392326.

Hendry, D. F., \& Muellbauer, J. N. (2018). The future of macroeconomics: macro theory and models at the Bank of England. Oxford Review of Economic Policy, 34(1/2), 287-328. https://doi.org/10.1093/oxrep/grx055

Hodrick, R. J., \& Prescott, E. C. (1997). Postwar US business cycles: an empirical investigation. Journal of Money, credit, and Banking, 1-16. https://doi.org/10.2307/2953682

Ifrim, A. (2014). Estimation of the Basic New Keynesian Model for the Economy of Romania. Munich Personal RePEc Archive, Item Id: 63900.

Karlsson, S. (2013). Forecasting with Bayesian vector autoregression. In Handbook of economic forecasting (Vol. 2, pp. 791-897). Elsevier. https://doi.org/10.1016/B978-0-444-62731-5.00015-4

Kolasa, M. (2009). Structural heterogeneity or asymmetric shocks? Poland and the euro area through the lens of a twocountry DSGE model. Economic Modelling, 26(6), 1245-1269. https://doi.org/10.1016/j.econmod.2009.06.001

Kolasa, M., \& Rubaszek, M. (2015). Forecasting using DSGE models with financial frictions. International Journal of Forecasting, 31(1), 1-19. https://doi.org/10.1016/j.ijforecast.2014.05.001.

Koop, G. M. (2003). Bayesian econometrics. John Wiley \& Sons Inc.

Korinek, A. (2017). Thoughts on DSGE Macroeconomics: Matching the Moment, But Missing the Point?. But Missing the Point. Available at SSRN, https://doi.org/10.2139/ssrn.3022009

Kydland, F. E., \& Prescott, E. C. (1982). Time to build and aggregate fluctuations. Econometrica: Journal of the Econometric Society, 1345-1370. https://doi.org/10.2307/1913386

Liu, G. D., \& Gupta, R. (2007). A small-scale DSGE model for forecasting the South African economy. South African Journal of Economics, 75(2), 179-193. https://doi.org/10.1111/j.1813-6982.2007.00118.x

Long Jr, J. B., \& Plosser, C. I. (1983). Real business cycles. Journal of political Economy, 91(1), 39-69. https://doi.org/10.1086/261128

Macias, P., \& Makarski, K. (2013). Stylizowane fakty o cenach konsumenta w Polsce. Narodowy Bank Polski. Departament Edukacji i Wydawnictw.

OECD. (2020). OECDiLibrary. Available from internet: https://www.oecd-ilibrary.org/economics/inflationcpi/indicator/english_eee82e6e-en, May 30, 2020.

Pollitt, H., 2020, Coronavirus: how to model the economic impacts of a pandemic, Available from internet: https://www.camecon.com/blog/coronavirus-how-to-model-the-economic-impacts-of-a-pandemic/, June 7, 2020.

Prescott, E. C. (1986). Theory ahead of business-cycle measurement. In Carnegie-Rochester conference series on public policy (Vol. 25, pp. 11-44). North-Holland. https://doi.org/10.1016/0167-2231(86)90035-7

Rubaszek, M., \& Skrzypczynski, P. (2008). On the forecasting performance of a small-scale DSGE model. International Journal of Forecasting, 24(3), 498-512. https://doi.org/10.1016/j.ijforecast.2008.05.002

Smets, F., \& Wouters, R. (2004). Forecasting with a Bayesian DSGE model: an application to the euro area. JCMS: Journal of Common Market Studies, 42(4), 841-867. https://doi.org/10.1111/j.0021-9886.2004.00532.x

Stiglitz, J. E. (2018). Where modern macroeconomics went wrong. Oxford Review of Economic Policy, 34(1/2), 70-106. https://doi.org/10.1093/oxrep/grx057

Walsh, C. E. (2017). Monetary theory and policy. MIT press.

Wesołowski, G. (2018). Do long-term interest rates drive GDP and inflation in small open economies? Evidence from Poland. Applied Economics, 50(57), 6174-6192. https://doi.org/10.1080/00036846.2018.1489507

Woodford, M. (2001). The Taylor rule and optimal monetary policy. American Economic Review, 91(2), $232-237$. https://pubs.aeaweb.org/doi/pdf/10.1257/aer.91.2.232 


\section{Authors' biographies}

Janusz Sobieraj is an Assistant Professor in the Department of Building Engineering, Faculty of Civil Engineering at the Warsaw University of Technology. He is a civil engineer with a degree from the Warsaw University of Technology, and holds a PhD in economic sciences in the field of management sciences from the Department of Computer Science and Management of the Wroclaw University of Technology. He is an author of several books on construction management, strategic management, and industrial revolution 4.0. His research interests are primarily in the areas of construction management, entrepreneurship, applied economics, mobility factors, productivity, organisations and management, and technologies. ORCID http://orcid.org/0000-0002-0819-7384

Dominik Metelski is a Research Assistant in the Department of Spanish and International Economics at the University of Granada (Spain). He is an economist with a degree from the University of Warsaw, and holds a PhD in the field of economic sciences from the Department of International Economics of the University of Granada, under the Programme of Studies on Advanced Techniques in Financial and Commercial Planning, Management and Control. His research interests are primarily related to such topics as productivity, migration as well as issues in the areas of entrepreneurship, innovation, real options and financial markets with particular emphasis on companies' valuations, portfolio management and financial options. ORCID http://orcid.org/0000-0003-0195-0342

The article has been reviewed.

Received in July 2020; accepted in April 2021.

This article is an Open Access article distributed under the terms and conditions of the Creative Commons Attribution 4.0 (CC BY 4.0) License (http://creativecommons.org/licenses/by/4.0/). 